\title{
Risk factors for polypharmacy in older adults in a primary care setting: a cross-sectional study
}

This article was published in the following Dove Press journal:

Clinical Interventions in Aging

\author{
Suleyman Ersoy' \\ Velittin Selcuk Engin ${ }^{2}$ \\ 'Department of Family Medicine, \\ Faculty of Medicine, Karabuk \\ University, Karabuk, Turkey; \\ ${ }^{2}$ Melekhatun Family Practice Center, \\ Ministry of Health, Istanbul 34340 , \\ Turkey
}

Purpose: Polypharmacy (PP) is a clinical challenge in older adults. Therefore, assessment of daily drug consumption (DDC) and its relationships is important. First-line health services have a crucial role in monitoring and preventing PP. In this study, we aimed to assess DDC and investigate the risk factors for higher DDC among older adults in a primary care setting.

Patients and methods: A total of 1,000 patients aged $\geq 65$ years who visited Melek Hatun Family Practice Center between December 1, 2014, and August 1, 2017, were enrolled in the study. All patients were seen either at the center or in their homes, and informed consent was obtained. Comprehensive geriatric assessment was performed for each subject. Data were analyzed using SPSS software (version 17). The daily number of medicines that each patient used (DDC) regardless of whether they were prescribed was the dependent variable. Relationships between DDC and other continuous variables were examined using Pearson's correlation. For between-group comparisons of DDC, Student's $t$-tests were performed.

Results: Univariate tests showed relationships between DDC and various demographic and clinical parameters. The variables that remained significant at the last step of a stepwise linear regression analysis were metabolic syndrome, chronic pain, incontinence, increased serum creatinine level, increased Geriatric Depression Scale scores, reported gastric disturbances, and neutrophil/lymphocyte ratio.

Conclusion: Along with certain chronic conditions, depressive symptoms and an inflammatory marker (neutrophil/lymphocyte ratio) were significantly and independently related to higher DDC. Longitudinal and larger studies are needed to further explore the multifaceted relationships of PP.

Keywords: polypharmacy, older adult, primary care, Geriatric Depression Scale, metabolic syndrome, neutrophil/lymphocyte ratio

\section{Introduction}

Life expectancy keeps increasing worldwide. The global population aged $\geq 60$ years is expected to grow by $56 \%$ between 2015 and 2030, with the fastest growth in urban settings of developing regions. ${ }^{1}$ According to the Turkish Statistical Institute, the older population amounted for $6,895,385$ and constituted $8.5 \%$ of the general population in 2017 , but it is expected that these numbers will increase to 8.6 million and $10.2 \%$ by $2023 .{ }^{2}$ These circumstances increase the burden of chronic diseases. In western countries, the older population constitutes $15 \%$ of the total population, and they account for $40 \%$ of the general health expenditure. ${ }^{3}$ In older adults, multimorbidity (which increases with age) also increases the consumption of medications and the risk of polypharmacy (PP), which is defined by the World Health Organization (WHO) as "the administration of many drugs at the same time or the administration of an excessive number of drugs." ${ }^{4}$ Although the WHO has suggested a threshold of $\geq 5$ per day, quantification of PP remains controversial. ${ }^{5,6}$
Correspondence: Suleyman Ersoy Department of Family Medicine, Faculty of Medicine, Karabuk University, Alparslan cad. Sirinevler, Karabuk, Turkey Tel +90505262800I

Email suleymanersoy@gmail.com 
PP is a major challenge especially in older patients. Additionally, medicine consumption without a prescription is rather common. A study of older Turkish adults reported that only $52.6 \%$ of the consumed medicines had been prescribed by a physician, while $21.1 \%$ were taken based on the patients' own decisions. Regarding other medication consumption, $13.2 \%$ was due to a friend's advice, $7.9 \%$ was due to a pharmacist's advice, and $5.25 \%$ was due to a neighbor's advice. ${ }^{7}$

Clinicians must be provided with proper guidance for rational management of medical treatment. To achieve this, information of relevant risks is essential. As the human body ages, the ability to eliminate drugs decreases gradually. Therefore, older adults are more susceptible to treatment side effects. ${ }^{8}$ It has been shown that as risk factors in geriatric syndromes accumulate, they create a synergistic effect regarding increasing the risk of developing new health conditions. PP, which is included in some geriatric syndrome criteria, is not only a problem that often goes unnoticed but also an indicator of morbidity and iatrogenesis risk. ${ }^{9,10}$ As medicine use for older patients is indispensable, proper assessment of daily drug consumption (DDC) as well as risk factors of $\mathrm{PP}$ in this population is of paramount importance.

First-line health services have a crucial role in monitoring and preventing PP. Thus, studies that conducted in first-line settings in older patients investigating the risks of PP will be of merit both for individual patients and in terms of health policies. The aim of this study was to assess DDC and investigate the risk factors for higher DDC among older adults in a primary care setting.

\section{Materials and methods Study design: This was a cross- sectional study}

Setting and sampling: The study was conducted at Melek Hatun Family Practice Center where approximately 20,000 patients were registered to receive primary health care. The number of patients aged $\geq 65$ years was about 2,500 . Sample size was calculated using the Epi Info program (Centers for Disease Control and Prevention, Atlanta, GA, USA) with 50\% expected frequency, 5\% acceptable margin of error, and $99.99 \%$ confidence level. To reach the calculated sample size, which was 943, all the patients (rather than random sampling from the population) aged $\geq 65$ years who applied to Melek Hatun Family Practice Center either in person or through a relative between December 1, 2014, and August 1, 2017, were enrolled in the study. The only exclusion criteria was patient's objection to participation, but all patients who applied to the health center during the specified interval agreed to take part in the study.

Data collection: All the patients were seen either at the center or in their homes, and written informed consent was obtained from them.

Baseline variables: Detailed history taking included demographic information, education level, number of members in the household, monthly income (as a continuous variable), presence of medical insurance, presence of handicap due to either physical disability or hearing and/or vision impairment, other body functions such as sleep and appetite, problems such as inadequate fluid intake or constipation, history of health complaints such as urinary incontinence (UI), dizziness, falls, gastric disturbances, and accounts of previously diagnosed chronic diseases such as heart failure or diabetes.

Dependent variable: Drug consumption information was obtained by the examining physician using the so-called "brown bag test" in which the patient was asked to collect all the medicines that he/she was currently using (including prescribed and over-the-counter medication) in a bag and bring it to the physician. Temporary medicines were later excluded.

Comprehensive geriatric assessment: All patients underwent physical examination including the assessment of body mass index (BMI, which is the ratio of body weight to the square of height) and waist circumference (WC, which was measured according to the STEPS protocol). BMI and WC were used as continuous values. ${ }^{11}$

Timed Up and Go (TUG) test: To assess each patient's mobility, he/she was asked to rise from a chair, walk $3 \mathrm{~m}$, turn, walk back, and sit down. A patient without a mobility restriction would complete this task within 14 seconds. ${ }^{12,13}$

Activities of Daily Living and Instrumental Activities of Daily Living scales (ADL and IADL): ADL consists of five self-care measures, while IADL included seven more complicated tasks. Scoring is undertaken using a 3-point ordinal scale, ranging from 0 to 2 . 0 point indicates inability, 1 indicates ability to do the task with aid, and 2 indicates ability to do it independently. The maximum score is 10 for the ADL and 14 for the IADL. ${ }^{14,15}$

Tinetti Performance Oriented Mobility Assessment Tool Balance and Gait scores: These assessments are used to evaluate an older adult's balance and mobility.

Tinetti Balance (TB): The patient was asked to sit in an armless chair and then to stand up. While standing, he/she must stay in balance when being lightly pushed either in neutral position or eyes closed. He/she then attempted to 
turn around completely without losing balance. The patient was also observed while sitting down. The maximum score is $16 .^{16}$

Tinetti Gait (TG): The patient walked on a straight path at a fast but safe speed. Step symmetry and equality as well as contact with the floor were observed. The patient could use assistive devices. The maximum score is 12 . This tool has a sensitivity of $70 \%$ and a specificity of $52 \%$. People who have a total score of $\leq 26$ have a 2 -fold risk of falling. ${ }^{17}$

Clock Drawing (CD) test: The patient was asked to draw a full clock showing a definite time such as 11:10. The maximum score is $6 .^{18}$

Mini Mental State Examination (MMSE): This tool was developed by Folstein. It consists of 30 items that assess cognitive abilities such as orientation, memory, attention, and language. The maximum score is $30 .{ }^{19} \mathrm{~A}$ Turkish version of the MMSE was validated for older Turkish adults. ${ }^{20}$ Another version was developed and validated for illiterate Turkish citizens, which was used for the illiterate participants in this study. ${ }^{21,22}$

Geriatric Depression Scale (GDS): This tool was first developed by Yesavage et al. ${ }^{23}$ It investigates depressive symptoms based on an older adult's responses to 30 yes/no questions. The patient must consider how he/she felt during the last few weeks. The occurrence of $\geq 14$ depressive answers has been reported to be indicative of depressive $\operatorname{mood}^{23,24}$

Three types of sleep disorders were questioned: Daytime sleepiness, interrupted sleep, and onset insomnia.

Additional tests: Tests such as blood examinations or electrocardiogram (ECG) were performed on the basis of necessity. Metabolic syndrome was diagnosed according to the WHO criteria. $^{25}$

\section{Data analysis}

Data were analyzed using SPSS software (version 17, SPSS Inc., Chicago, IL, USA). The daily number of medicines that each patient used (DDC) was the dependent variable. The relationships between DDC and other continuous variables were examined by Pearson's correlation. For betweengroup comparisons of the mean DDC, Student's $t$-tests were performed. To detect probable independent risk factors for DDC, related variables as well as possible confounders were added in a backward stepwise linear regression analysis. To avoid collinearity problems, variables that were strongly interrelated were not added to the regression model together (eg, TB test score was added without TG score, and serum creatinine was added without chronic renal failure $[\mathrm{CRF}]$ ).
These were the independent variables added in the model: age, sex, outpatient status, coronary syndromes, TB score, $\mathrm{WC}$, inadequate fluid intake, gastric disturbances, chronic obstructive pulmonary disease, major trauma, hypertension, atrial fibrillation, heart failure, dementia, serum creatinine, neutrophil/lymphocyte ratio (NLR), osteoporosis, daytime sleepiness, sleep onset insomnia, chronic pain, stroke, UI, GDS score, metabolic syndrome, restricted mobility detected by TUG test, falls, and IADL score. For all analyses, the level of significance was 0.05 . The "qvalue" package in $\mathrm{R}$ (version 3.5.1, The R Foundation, Vienna, Austria) was employed to adjust for the false discovery rate. ${ }^{26,27}$

\section{Ethics approval and informed consent}

The study was approved by Karabuk University Clinical Research Ethic Committee on 31.05.2017, number 5/3. All procedures performed in studies involving human participants were in accordance with the ethical standards of the institutional and/or national research committee and with the 1964 Helsinki declaration and its later amendments or comparable ethical standards.

\section{Results}

Sociodemographic data: As shown in Table 1, 624 (62.4\%) women and $376(37.6 \%)$ men took part in the study. Regarding where the patients were assessed, 536 patients were seen $(53.6 \%)$ at the outpatient clinic, while 464 patients (46.4\%) were visited at home. Regarding age, 600 of the subjects (60\%) were aged 65-74 years, 301 (30.1\%) were 75-84 years, and $99(9.9 \%)$ were $\geq 85$ years. The mean age was $73.74 \pm 7.23$ years. Among the subjects, 79 (7.9\%) lacked health insurance. Regarding education, 376 of the subjects were illiterate, $612(61.2 \%)$ had completed elementary school, 10 (1\%) had graduated from high school or equivalent, while only $2(0.2 \%)$ had a university degree. The mean education duration was $3.34 \pm 3.33$ years.

DDC and associated factors: The mean DDC was $4.63 \pm 3.51$, and the mean number of chronic diseases was $4.02 \pm 1.97$. The mean DDC was higher for female patients than for male patients, but the difference was not significant $(P=0.087$ ) (Table 1). The relationship between DDC and education was found to be nonsignificant in regard to both literacy and years of education. ( $P=0.24$ and 0.065 , respectively) (Tables 2 and 3). Age was strongly correlated with DDC $(P<0.001)$ (Table 3$)$. The patients who were handicapped or had TUG restrictions had significantly higher DDC ( $P=0.019$ and 0.001 , respectively). However, the patients who were seen at home had lower DDC $(P=0.001)$. 
Table I Descriptive variables and DDC

\begin{tabular}{|c|c|c|c|c|}
\hline Variable & $\mathbf{N}$ & Percent & $\mathbf{D D C} \pm$ SD & $P$-value \\
\hline Overall & 1,000 & 100.00 & $4.63 \pm 3.51$ & \\
\hline Female & 624 & 62.4 & $4.77 \pm 3.3$ & \multirow{2}{*}{0.087} \\
\hline Male & 376 & 37.6 & $4.29 \pm 3.7$ & \\
\hline Outpatient clinic & 536 & 53.6 & $5.31 \pm 3.7$ & \multirow{2}{*}{0.001708} \\
\hline Home visit & 464 & 46.4 & $3.76 \pm 3.6$ & \\
\hline Educated & 614 & 61.4 & $4.72 \pm 3.4$ & \multirow{2}{*}{0.24} \\
\hline Illiterate & 376 & 37.6 & $4.39 \pm 3.0$ & \\
\hline With health insurance & 911 & 91.1 & $4.79 \pm 3.5$ & \multirow{2}{*}{$0.001708^{a}$} \\
\hline No health insurance & 79 & 7.9 & $2.56 \pm 2.9$ & \\
\hline
\end{tabular}

Note: 'Relationship is statistically significant in Student's $t$-test $(P<0.05)$ (adjusted $P$-values obtained via FDR).

Abbreviations: FDR, false discovery rate; DDC, daily drug consumption.

Table 2 Associations between health conditions and DDC

\begin{tabular}{|c|c|c|c|c|c|}
\hline Health condition & $\mathbf{N}^{\mathbf{a}}$ & $\begin{array}{l}\text { Present } \\
(\text { mean DDC } \pm S D)\end{array}$ & $\mathbf{N}^{\mathbf{b}}$ & $\begin{array}{l}\text { Not present } \\
(\text { mean DDC } \pm S D)\end{array}$ & $P$-value \\
\hline Diabetes & 736 & $6.26 \pm 3.9$ & 394 & $3.94 \pm 3.1$ & $0.001708^{c}$ \\
\hline IGT & 218 & $5.91 \pm 3.0$ & 792 & $4.94 \pm 3.2$ & $0.001708^{c}$ \\
\hline Metabolic syndrome & 406 & $6.28 \pm 3.6$ & 594 & $4.52 \pm 3.0$ & $0.001708^{c}$ \\
\hline Hypertension & 726 & $5.30 \pm 3.4$ & 274 & $2.46 \pm 2.6$ & $0.001708^{c}$ \\
\hline CAD & 230 & $6.43 \pm 5.7$ & 770 & $3.98 \pm 3.2$ & $0.001708^{c}$ \\
\hline Atrial fibrillation & 63 & $7.03 \pm 4.3$ & 937 & $5.06 \pm 3.4$ & $0.001708^{c}$ \\
\hline Heart failure & 147 & $6.52 \pm 3.5$ & 853 & $4.26 \pm 3.4$ & $0.001708^{c}$ \\
\hline Chronic obstructive pulmonary disease & 169 & $5.68 \pm 3.6$ & 831 & $4.34 \pm 3.4$ & $0.001708^{c}$ \\
\hline History of depression & 177 & $6.96 \pm 4.1$ & 823 & $4.09 \pm 3.1$ & $0.001708^{c}$ \\
\hline Osteoporosis & 187 & $5.88 \pm 3.6$ & 813 & $4.30 \pm 3.4$ & $0.001708^{c}$ \\
\hline CRF & 65 & $5.63 \pm 3.5$ & 935 & $4.45 \pm 3.4$ & $0.001708^{c}$ \\
\hline Anemia & 157 & $5.96 \pm 3.5$ & 843 & $5.21 \pm 3.5$ & 0.057622 \\
\hline Dementia & 68 & $6.49 \pm 4.1$ & 932 & $4.46 \pm 3.4$ & $0.001708^{c}$ \\
\hline Handicapped & $|4|$ & $5.4 \pm 4.1$ & 859 & $4.45 \pm 3.3$ & $0.019839^{\circ}$ \\
\hline Trauma history & 369 & $5.45 \pm 3.6$ & 631 & $4.06 \pm 3.3$ & $0.001708^{c}$ \\
\hline Stroke & 108 & $5.86 \pm 3.7$ & 892 & $4.43 \pm 3.4$ & $0.001708^{c}$ \\
\hline Chronic pain & 511 & $5.63 \pm 3.6$ & 489 & $3.52 \pm 3.0$ & $0.001708^{c}$ \\
\hline UI & 247 & $6.29 \pm 4.0$ & 753 & $3.74 \pm 4.7$ & $0.001708^{c}$ \\
\hline Dizziness & 392 & $5.5 I \pm 3.1$ & 608 & $4.86 \pm 3.3$ & $0.04 I^{c}$ \\
\hline Falls & 281 & $5.56 \pm 3.9$ & 719 & $4.23 \pm 3.2$ & $0.001708^{c}$ \\
\hline POT $^{d}$ & 212 & $5.78 \pm 3.4$ & 788 & $4.86 \pm 3.3$ & $0.008483^{\circ}$ \\
\hline Daytime sleepiness & 327 & $5.74 \pm 4.0$ & 673 & $4.79 \pm 3.0$ & $0.005857^{\circ}$ \\
\hline Sleep onset insomnia & 345 & $5.52 \pm 3.7$ & 655 & $4.86 \pm 3.2$ & $0.037486^{\circ}$ \\
\hline Interrupted sleep & 306 & $5.67 \pm 3.8$ & 694 & $4.85 \pm 3.2$ & $0.0164^{c}$ \\
\hline Restricted mobility & 372 & $5.29 \pm 3.9$ & 628 & $4.16 \pm 3.1$ & $0.001708^{c}$ \\
\hline Gastric disturbances & 416 & $5.85 \pm 3.6$ & 584 & $3.73 \pm 3.2$ & $0.001708^{c}$ \\
\hline
\end{tabular}

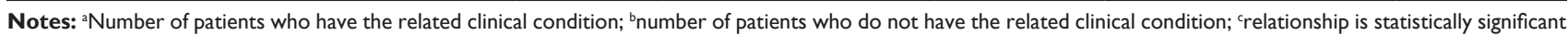
in Student's $t$-test $(P<0.05)$ (adjusted $P$-values obtained via FDR); 'heart rate increase of 30 beats per minute $(\mathrm{bpm})$ or more, or over $120 \mathrm{bpm}$, within the first 10 minutes of standing, in the absence of orthostatic hypotension; 65 eaccording to TUG test. ${ }^{12}$

Abbreviations: CAD, coronary artery disease; CRF, chronic renal failure; DDC, daily drug consumption; FDR, false discovery rate; IGT, impaired glucose tolerance; POT, postural orthostatic tachycardia; TUG, Timed Up and Go; UI, urinary incontinence. 
Table 3 Correlations between continuous variables and DDC

\begin{tabular}{|l|l|l|}
\hline \multirow{2}{*}{ Variable } & \multicolumn{2}{|l|}{ DDC } \\
\cline { 2 - 3 } & $\begin{array}{l}\text { Correlation } \\
\text { coefficient }(\boldsymbol{r})\end{array}$ & $P$-value \\
\hline Age & $0.135^{\mathrm{a}}$ & 0.000 \\
\hline BMI & $0.145^{\mathrm{a}}$ & 0.001708 \\
\hline WC & $0.148^{\mathrm{a}}$ & 0.001708 \\
\hline Education (years) & 0.072 & 0.065816 \\
\hline Income & 0.078 & 0.077795 \\
\hline CD test score & -0.046 & 0.299 \\
\hline ADL score & 0.048 & 0.218325 \\
\hline IADL score & $-0.090^{\mathrm{a}}$ & 0.026091 \\
\hline Serum creatinine & $0.143^{\mathrm{a}}$ & $0.00473 \mathrm{I}$ \\
\hline MMSE score & & 0.034971 \\
\hline TB score & $0.086^{\mathrm{a}}$ & 0.004731 \\
\hline TG score & $-0.130^{\mathrm{a}}$ & 0.005857 \\
\hline GDS score & $-0.125^{\mathrm{a}}$ & 0.001708 \\
\hline NLR & $0.133^{\mathrm{a}}$ & 0.024344 \\
\hline Number of chronic diseases ${ }^{\mathrm{d}}$ & $0.119^{\mathrm{a}}$ & 0.000 \\
\hline
\end{tabular}

Notes: ${ }^{a}$ Relationship is statistically significant in Pearson's correlation $(P<0.05)$ (adjusted $P$-values obtained via FDR); bthe illiterate subjects were unable to gain > I point in the CD test; 'relationship is inverse; ' $a c c o r d i n g$ to Alwan: ${ }^{66} \mathrm{Global}$ Status Report on Noncommunicable Diseases 2010.

Abbreviations: ADL, Activities of Daily Living; BMI, body mass index; CD, Clock Drawing; DDC, daily drug consumption; FDR, false discovery rate; GDS, Geriatric Depression Scale; IADL, Instrumental Activities of Daily Living; MMSE, Mini Mental State Examination; NLR, neutrophil/lymphocyte ratio; TB, Tinetti Balance; TG, Tinetti Gait.

Other relationships of categorical variables with DDC are shown in Tables 1 and 2, while Table 3 shows the correlations of continuous variables with DDC.

TB and TG scores $(P=0.004$ and 0.005 , respectively), GDS score $(P=0.001)$, BMI $(P=0.001)$, and WC $(P=0.001)$ were positively correlated with DDC, whereas MMSE score was negatively correlated $(P=0.034)$. DDC was not correlated with either $\mathrm{CD}$ test score $(P=0.299)$ or ADL score
$(P=0.218)$. Nonetheless, a positive correlation with IADL score $(P=0.026)$ was seen. Serum creatinine level $(P=0.004)$ and NLR $(P=0.024)$ were also significantly correlated with DDC. As expected, the number of chronic diseases had the strongest correlation (correlation coefficient $=0.538$, $P<0.001$ ) (Table 3).

Multiple regression results: The variables that remained significant at the last (14th) step of the multiple regression analysis were metabolic syndrome, chronic pain, incontinence, increased serum creatinine level, increased GDS score, reported gastric disturbances, and NLR (Table 4).

\section{Discussion}

In the present study, we investigated DDC and related factors in older adults in a primary care setting. The mean DDC in the whole group was $4.63 \pm 3.51$. In female and male subgroups, the mean DDC was 4.77 \pm 3.3 and 4.29 \pm 3.7 , respectively. In a retrospective review of hospital records of 1,205 geriatric patients who had applied to be treated at the University of Istanbul, the mean DDC was $4.36,{ }^{28}$ which is similar to our finding. In studies in different regions of Turkey, the mean DDC ranged from 2.18 to $4.50 .{ }^{29-32}$ These results suggest that there may be regional differences in terms of DDC. ${ }^{33}$

There seems to be international differences regarding DDC as well. A study in Germany reported that older primary care patients used 3.7 prescribed medicines and an additional 1.4 over-the-counter drugs. ${ }^{5}$ A Swedish study of 1,347,564 individuals aged $\geq 65$ years reported that DDC ranged from 0 to 40 drugs with a median of 4 , whereas the median number was 3.5 in 2 Belgian studies. ${ }^{34,35}$ In a retrospective study of older Italian patients, the mean DDC was $6.3 \pm 4.2{ }^{6}$

There are contradictory results regarding gender differences in DDC. According to the Kuopio 75+ study and a study in Spain, female sex was significantly associated with

Table 4 Risk factors for higher DDC after regressions

\begin{tabular}{|l|l|l|l|l|l|}
\hline \multirow{2}{*}{ Variable } & \multicolumn{2}{l|}{ Unstandardized coefficients } & \multirow{2}{*}{ P-value } & \multicolumn{2}{l|}{ 95\% confidence interval } \\
\cline { 2 - 4 } & B & Standard error & & Lower & Upper \\
\hline Constant & 0.96 & 0.66 & 0.15 & -0.342 & 2.257 \\
\hline Metabolic syndrome & 1.45 & 0.39 & $<0.0001$ & 0.677 & 2.217 \\
\hline Chronic pain & 0.84 & 0.41 & 0.043 & 0.028 & 1.649 \\
\hline UI & 0.99 & 0.41 & 0.016 & 0.186 & 1.786 \\
\hline Creatinine & 1.08 & 0.37 & 0.004 & 0.351 & 1.817 \\
\hline Geriatric depression scale & 0.07 & 0.03 & 0.009 & 0.017 & 0.120 \\
\hline Gastric disturbances & 0.95 & 0.38 & 0.012 & 0.206 & 1.688 \\
\hline NLR & 0.327 & 0.122 & 0.008 & 0.087 & 0.568 \\
\hline
\end{tabular}

Note: Statistically significant in backward stepwise linear regressions $(P<0.05)$.

Abbreviations: DDC, daily drug consumption; NLR, neutrophil/lymphocyte ratio; UI, urinary incontinence. 
higher DDC. ${ }^{36,37}$ However, it was also reported that older men in Malaysia had a 1.09-fold increased risk of PP compared to older women. ${ }^{38}$ Additionally, there are studies in which no significant difference was found between male and female subjects. ${ }^{35,39}$ Although the mean DDC was slightly higher in women compared to men, the difference was not significant in our study.

In our study, metabolic syndrome, chronic pain, UI, increased creatinine levels, increased GDS score, reported gastric disturbances, and NLR were found to be independent risk factors for DDC.

As for GDS, we could not find a relevant study on GDS in the literature. However, there are studies reporting associations of depression with PP. Recently diagnosed depression was found significantly associated with PP in older adults. ${ }^{35}$ The Kuopio study reported that depression was significantly associated with PP in patients aged $>75$ years. ${ }^{37}$ Also, a study that assessed depression in nursing home residents in various European countries reported similar findings. ${ }^{40}$

Misawa et $\mathrm{al}^{41}$ found no significant difference in metabolic syndrome prevalence between monotherapy and PP groups $(23.4 \%$ vs $21.0 \% ; P=0.60)$ among patients taking antipsychotics. On the other hand, the PP group was more likely to have pre-metabolic syndrome (46.7\% vs $34.1 \%$; $P=0.019) .{ }^{41}$ Misawa et al ${ }^{41}$ suggested that these results might indicate a relationship between PP involving multiple antipsychotics and metabolic syndrome. Correll et al ${ }^{42}$ also found that compared to monotherapy patients taking one antipsychotic, those taking two or three antipsychotics were more likely to have metabolic syndrome (50.0\% vs $34.4 \%$; $P=0.015)$. They implied that patients receiving antipsychotic PP had poorer metabolic health, but this does not indicate that metabolic syndrome is an independent risk factor, as there are important confounding contributors to antipsychotic PP such as inactivity. ${ }^{42}$ Another study reported that higher DDC was independently associated with metabolic syndrome in older Malaysians. ${ }^{43}$ Our regression analyses yielded the same result.

Older adults suffer painful conditions such as chronic, neuropathic, and arthropathic pain more often. It is well known that chronic pain is one of the main causes of PP in this population. ${ }^{44,45}$ An Australian study revealed that presence of pain was significantly associated with PP in institutionalized older adults. ${ }^{46}$ Pain was also found to be strongly related to PP in cognitively impaired older adults $(P<0.001) .{ }^{47}$ The Shelter study also revealed the same for older nursing home residents $(P<0.001) .{ }^{40}$ Chronic pain is often associated with comorbidities that can be classified into three major groups: 1) behavioral comorbidities (psychiatric) that can be diagnosed according to the Diagnostic and Statistical Manual of Mental Disorders, 2) behavioral comorbidities (psychological) devoid of Diagnostic and Statistical Manual of Mental Disorders criteria, and 3) somatic comorbidities with or without a behavioral component. ${ }^{48}$ The propensity for comorbidities in patients with chronic pain may also account for the relevance of chronic pain to PP, in addition to the patients' tendency toward excessive analgesic consumption. Nevertheless, chronic pain was independently associated with increased DDC in our study.

Gastric disturbances were also an independent risk factor in our study. It has been reported that the most commonly prescribed medications are for gastrointestinal diseases. ${ }^{49}$ However, consumption of an excessive number of drugs or inappropriate medications often brings about adverse reactions. Gastric disturbances are one of the most common types of adverse reactions. ${ }^{50}$ Some patients resort to gastrointestinal drugs such as proton pump inhibitors or antacids to alleviate or avoid the side effects of their medications. These attempts lead to "treatment cascades" and increase DDC. Other studies designed to investigate $\mathrm{PP}$ in various patient groups reported similar results. ${ }^{51-53}$

In our study, UI remained significantly associated with increased DDC in the final step of the regression analysis. Like PP, UI is also one of the most common problems in older adults, and there is sufficient evidence suggesting an association with PP. In a cross-sectional study of 1,705 older adults, PP was among the factors associated with UI. ${ }^{54}$ In another study aiming to determine the medications that may contribute to urinary symptoms in patients aged $\geq 60$ years, only PP (odds ratio $=4.9,95 \% \mathrm{CI}=3.1-7.9$ ) was found to be significantly associated with UI. ${ }^{55}$ The medications used for UI increase the risk for PP and, on the other hand, PP can precipitate the onset of UI. ${ }^{56,57}$ Diuretics are the most common medications that cause UI. ${ }^{58}$

Glomerular and tubular function decrease and serum creatinine increases with age. As kidney functions are impaired by disease and age-related changes, excretion of drugs is hampered. Therefore, inappropriate medication intake is a matter of greater concern in older adults, especially in those with diagnosed renal function impairment. Despite this, there is insufficient concern regarding the necessity of avoiding further deterioration. A study of patients aged $>70$ years previously diagnosed with chronic kidney disease reported that a mean number of 6.2 drugs per patient had been prescribed and $13 \%$ of all medications were potentially inappropriate. ${ }^{59}$ In a similar study, Blix et $\mathrm{al}^{60}$ found that the mean number 
of drugs prescribed per patient was higher for the impaired renal function group compared to the control group (6.2 vs 4.1). The authors pointed out that the former group had more comorbidities, such as diabetes, hypertension, and cardiac diseases, which increased the mean medicine consumption and also may have facilitated renal impairment. ${ }^{60}$ It is safe to say that the risk of medication-induced nephrotoxicity increases with increasing numbers of medications. Therefore, older adults are especially prone to being on potentially nephrotoxic medication regimens. CRF was significantly associated with increased DDC in our study. To avoid collinearity, only serum creatinine level (rather than CRF) was added to the regression analysis, and it remained significant in the last step.

Another interesting finding in this study was that NLR was an independent risk factor for increased DDC. Defined as the neutrophil count divided by the lymphocyte count, NLR is considered a potentially beneficial indicator of nonspecific immune responses to a number of bodily stress conditions. Zahorec $^{61}$ suggested that NLR could be a measure of clinical severity in seriously decompensated patients. NLR has also been regarded as a promising marker of inflammation that might be used to estimate prognosis in various diseases such as cardiovascular problems and gastrointestinal malignancies. ${ }^{62,63}$ There are studies suggesting that NLR is an independent predictor of short- and long-term outcomes in acute coronary syndromes and stable coronary artery disease. ${ }^{64}$ It is known that NLR increases with inflammation; also, drugs are likely to be administered in conditions associated with inflammation. This may account for the link between DDC and increased NLR. Our study revealed a direct association between higher DDC and NLR. To the best of our knowledge, this is the first study indicating such a relationship.

We would like to outline the importance of first-line health services. Primary care is a major step in ensuring appropriate medical treatment. Primary care physicians have essential roles in ensuring that older patients' drug regimens are adequate and concise. To achieve this, they require multidisciplinary support involving specialists, pharmacists, and, optimally, a geriatric health care team. Collaboration with the older patient and their family members is also essential.

Another major strength of this study was its ability to determine independent relationships with DDC, a parameter that has many contributing factors. Last but not least, we found an independent correlation between DDC and NLR, suggesting a direct relationship between PP and inflammation, and potentially inspiring new studies on both subjects.
The limitations of our study include its cross-sectional design. Although important, our results cannot be extrapolated to big populations as the study was not longitudinal and also had a limited study sample. Furthermore, higher DDC can be a cause as well as a consequence, and sometimes both, according to the situation. For such a parameter, we cannot claim, based on our results, that we could reveal the exact directions of all its causal relationships.

\section{Conclusion}

In our study, univariate tests suggested associations between DDC and various demographic and clinical parameters. When other variables were controlled for in a multiple regression analysis, serum creatinine level and NLR were the laboratory factors that remained significantly associated with DDC. As for clinical conditions, metabolic syndrome, GDS score, UI, gastric disturbances, and chronic pain remained significantly associated with increased DDC in the last step of the multiple regression analysis. To understand the multifaceted relationships of PP in terms of its causes as well as outcomes, longitudinal studies of greater scale would be of benefit.

\section{Availability of data and material}

Written informed consent was obtained from all individual participants included in the study. The datasets used and/or analyzed during the current study and informed consent form are available from ClinicalTrials.gov Protocol Registration and Results System with ID number: NCT03524560 to any researcher.

\section{Acknowledgments}

The authors wish to thank Prof Seyit Ali Kayis and Prof Handan Ankarali for their kind help in statistical analysis. This research did not receive any specific grant from funding agencies in the public, commercial, or not-for-profit sectors.

\section{Author contributions}

SE was involved in study conception and design, constructing the hypothesis of research and article, taking responsibility in necessary literature review for the study, drafting the article (introduction and discussion) and revising the article, and final approval of the article. VSE was involved in the planning methodology to reach the conclusions, data collection, processing, and reporting, taking responsibility in patient follow-up, analysis and interpretation, drafting the article (methods and results), revising the article, and final approval of the article. All authors contributed toward data analysis, 
drafting and revising the paper and agreed to be accountable for all aspects of the work.

\section{Disclosure}

The authors report no conflicts of interest in this work.

\section{References}

1. United Nations Department of Economic and Social Affairs. World Population Aging. New York: United Nations Department of Economic and Social Affairs; 2015.

2. Turkey in Statistics, 2017. Turkish Institute of Statistics, data dissemination group. Census results 2017. Ankara, Turkey: Turkish Institute of Statistics; 2018.

3. Aydın ZD. Yaşlanan Dünya ve geriatri eğitimi [Aging world and the education in geriatrics]. Geriatri. 1999;(4):179-187.

4. WHO Centre for Health Development. A Glossary of Terms for Community Health Care and Services for Older Persons. Ageing and Health Technical Report. Geneva, Switzerland: World Health Organization; 2004.

5. Junius-Walker U, Theile G, Hummers-Pradier E. Prevalence and predictors of polypharmacy among older primary care patients in Germany. Fam Pract. 2007;24(1):14-19.

6. Slabaugh SL, Maio V, Templin M, Abouzaid S. Prevalence and Risk of Polypharmacy among the Elderly in an Outpatient Setting. Drugs Aging. 2010;27(12):1019-1028.

7. Arslan Şule, Atalay A, Gökçe-Kutsal Y. Yaşlılarda ilaç tüketimi [Drug use in elderly]. Geriatri. 2000;3(2):56-60.

8. Mangoni AA, Jackson SH. Age-related changes in pharmacokinetics and pharmacodynamics: basic principles and practical applications. Br J Clin Pharmacol. 2004;57(1):6-14.

9. Chao CT, Tsai HB, Wu CY, et al. Cumulative Cardiovascular Polypharmacy Is Associated With the Risk of Acute Kidney Injury in Elderly Patients. Medicine. 2015;94(31):e1251.

10. Takeuchi H, Suzuki T, Remington G, Uchida H. Antipsychotic Polypharmacy and Corrected QT Interval: A Systematic Review. Can $J$ Psychiatry. 2015;60(5):215-222.

11. World Health Organization. Waist Circumference and Waist-Hip Ratio: Report of a WHO Expert Consultation. Geneva: World Health Organization; 2008.

12. Podsiadlo D, Richardson S. The timed "Up \& Go": a test of basic functional mobility for frail elderly persons. J Am Geriatr Soc. 1991;39(2): 142-148.

13. Shumway-Cook A, Brauer S, Woollacott M. Predicting the probability for falls in community-dwelling older adults using the Timed Up \& Go Test. Phys Ther. 2000;80(9):896-903.

14. Katz S, Ford AB, Moskowitz RW, Jackson BA, Jaffe MW. Studies of illness in the aged. The index of ADL: A standardized measure of biological and psychosocial function. JAMA. 1963;185:914-919.

15. Lawton MP, Brody EM. Assessment of older people: self-maintaining and instrumental activities of daily living. Gerontologist. 1969;9(3): 179-186.

16. Tinetti ME. Performance-oriented assessment of mobility problems in elderly patients. J Am Geriatr Soc. 1986;34(2):119-126.

17. Raîche M, Hébert R, Prince F, Corriveau H. Screening older adults at risk of falling with the Tinetti balance scale. Lancet. 2000;356(9234): 1001-1002.

18. Rosen WG, Mohs RC, Davis KL. A new rating scale for Alzheimer's disease. Am J Psychiatry. 1984;141(11):1356-1364.

19. Folstein MF, Folstein SE, McHugh PR. "Mini-mental state". A practical method for grading the cognitive state of patients for the clinician. J Psychiatr Res. 1975;12(3):189-198.

20. Güngen C, Ertan T, Eker E, Yaşar R, Engin F. Reliability and validity of the standardized Mini Mental State Examination in the diagnosis of mild dementia in Turkish population. Turk Psikiyatri Derg. 2002; 13(4):273-281. Turkish.
21. Ertan T, Eker E, Güngen C, et al. The standardized mini mental state examination for Illiterate Turkish Elderly Population. In: 2nd International Symposium on Neurophysiological and Neuropsychological Assessment of Mental and Behavioral Disorders, August 28-30, 1999, Bursa, Turkey.

22. Babacan-Yıldız G, Ur-Özçelik E, Kolukısa M, et al. Validity and Reliability Studies of Modified Mini Mental State Examination (MMSE-E) For Turkish Illiterate Patients With Diagnosis of Alzheimer Disease. Turk Psikiyatri Derg. 2016;27(1):41-46. Turkish.

23. Yesavage JA, Brink TL, Rose TL, et al. Development and validation of a geriatric depression screening scale: a preliminary report. $J$ Psychiatr Res. 1982;17(1):37-49.

24. Montorio I, Izal M. The Geriatric Depression Scale: a review of its development and utility. Int Psychogeriatr. 1996;8(1):103-112.

25. Alberti KG, Zimmet P, Shaw J; IDF Epidemiology Task Force Consensus Group. The metabolic syndrome - a new worldwide definition. Lancet. 2005;366(9491):1059-1062.

26. R Core Team. R: A Language and Environment for Statistical Computing. Vienna, Austria: R Foundation for Statistical Computing; 2014.

27. Dabney A, Storey JD, Warnes GR. qvalue: Q-value estimation for false discovery rate control. $R$ package version. 2010;1(0).

28. Yuruyen M, Yavuzer H, Demirdag F, et al. Is Depression a Predictive Factor for Polypharmacy in Elderly? Klinik Psikofarmakoloji Bülteni (Bulletin of Clinical Psychopharmacology). 2016;26(4):374-381.

29. Yüksel GH, Ayșe NO. Drug Use among Elderly over 65 Years of Age Enrolled a Family Health Center in Pendik, İstanbul. Sted. 2016;6:225.

30. Esengen S, Seckin U, Borman P, Bodur H, Kutsal Y. The assessment of functional cognitive impairment and drug consumption in a group of elderly residents of a nursing home. Turk. J. Geriatr. 2000; $3: 6-10$

31. Dişcigil G, Tekinç N, Anadol Z, Bozkaya AO. Polypharmacy in nursing home and community - dwelling elderly. Turk. J. Geriatr. 2006; 9(3):117-121.

32. Gokce Kutsal Y, Barak A, Atalay A, et al. Polypharmacy in the elderly: a multicenter study. J Am Med Dir Assoc. 2009;10(7):486-490.

33. Çakmur H, Hülya. Factors Affecting Polypharmacy in Elderly in Two Different (Kars-İzmir) Cities of Turkey. Turkiye Klinikleri J Med Sci. 2014;34(1):71-80.

34. Wastesson JW, Canudas-Romo V, Lindahl-Jacobsen R, Johnell K. Remaining life expectancy with and without polypharmacy: a registerbased study of Swedes aged 65 years and older. J Am Med Dir Assoc. 2016;17(1):31-35.

35. Walckiers D, van der Heyden J, Tafforeau J, Johan VH, Jean T. Factors associated with excessive polypharmacy in older people. Arch Public Health. 2015;73(1):50.

36. Frutos Bernal E, Martín Corral JC, Galindo Villardón P. Factors related to polypharmacy in the non-institutionalised elderly. Analysis of the subsample of the national survey of health 2006 for the elderly in Castile-Leon. Rev Esp Geriatr Gerontol. 2011;46(6):303-306. Spanish.

37. Jyrkkä J, Vartiainen L, Hartikainen S, Sulkava R, Enlund H. Increasing use of medicines in elderly persons: a five-year follow-up of the Kuopio 75+Study. Eur J Clin Pharmacol. 2006;62(2):151-158.

38. Lim LM, McStea M, Chung WW, et al. Prevalence, risk factors and health outcomes associated with polypharmacy among urban community-dwelling older adults in multi-ethnic Malaysia. PLoS One. 2017; 12(3): 0173466.

39. Jörgensen T, Johansson S, Kennerfalk A, Wallander MA, Svärdsudd K. Prescription drug use, diagnoses, and healthcare utilization among the elderly. Ann Pharmacother. 2001;35(9):1004-1009.

40. Onder G, Liperoti R, Fialova D, et al; SHELTER Project. Polypharmacy in nursing home in Europe: results from the SHELTER study. $J$ Gerontol A Biol Sci Med Sci. 2012;67(6):698-704.

41. Misawa F, Shimizu K, Fujii Y, et al. Is antipsychotic polypharmacy associated with metabolic syndrome even after adjustment for lifestyle effects?: a cross-sectional study. BMC Psychiatry. 2011;11(1):118.

42. Correll CU, Frederickson AM, Kane JM, Manu P. Does antipsychotic polypharmacy increase the risk for metabolic syndrome? Schizophr Res. 2007;89(1-3):91-100. 
43. McStea M, McGeechan K, Kamaruzzaman SB, Rajasuriar R, Tan MP. Defining metabolic syndrome and factors associated with metabolic syndrome in a poly-pharmaceutical population. Postgrad Med. 2016;128(8):797-804.

44. Jokanovic N, Tan EC, Dooley MJ, Kirkpatrick CM, Elliott RA, Bell JS. Why is polypharmacy increasing in aged care facilities? The views of Australian health care professionals. J Eval Clin Pract. 2016; 22(5):677-682.

45. Paladini A, Fusco M, Coaccioli S, Skaper SD, Varrassi G. Chronic pain in the elderly: the case for new therapeutic strategies. Pain Physician. 2015;18(5):E863-E876.

46. Hubbard RE, Peel NM, Scott IA, et al. Polypharmacy among inpatients aged 70 years or older in Australia. Med J Aust. 2015;202(7): 373-377.

47. O’Dwyer M, Peklar J, McCallion P, McCarron M, Henman MC. Factors associated with polypharmacy and excessive polypharmacy in older people with intellectual disability differ from the general population: a cross-sectional observational nationwide study. BMJ Open. 2016;6(4):e010505.

48. Fishbain DA. Polypharmacy treatment approaches to the psychiatric and somatic comorbidities found in patients with chronic pain. Am J Phys Med Rehabil. 2005;84(3 Suppl):S56-S63.

49. Trumic E, Pranjic N, Begic L, Bečić F. Prevalence of polypharmacy and drug interaction among hospitalized patients: opportunities and responsibilities in pharmaceutical care. Mater Sociomed. 2012;24(2):68-72.

50. Hippius M, Hegenbart U. Drug-induced gastrointestinal disorders in surgical patients admitted to the University Hospital, Jena, Germany. Int J Clin Pharmacol Ther. 2005;43(8):406-410.

51. Kotlinska-Lemieszek A, Paulsen O, Kaasa S, Klepstad P. Polypharmacy in patients with advanced cancer and pain: a European crosssectional study of 2282 patients. J Pain Symptom Manage. 2014; 48(6):1145-1159.

52. Mcneil MJ, Kamal AH, Kutner JS, Ritchie CS, Abernethy AP. The burden of polypharmacy in patients near the end of life. J Pain Symptom Manage. 2016;51(2):178-183.e2.

53. Mizokami F, Koide Y, Noro T, Furuta K. Polypharmacy with common diseases in hospitalized elderly patients. Am J Geriatr Pharmacother. 2012;10(2):123-128.

54. Marques LP, Schneider IJ, Giehl MW, Antes DL, d'Orsi E. Demographic, health conditions, and lifestyle factors associated with urinary incontinence in elderly from Florianópolis, Santa Catarina, Brazil. Rev Bras Epidemiol. 2015;18(3):595-606. English, Portuguese.
55. Kashyap M, Tu Le M, Tannenbaum C. Prevalence of commonly prescribed medications potentially contributing to urinary symptoms in a cohort of older patients seeking care for incontinence. BMC Geriatr. 2013;13:57.

56. Hogan DB. Revisiting the $\mathrm{O}$ complex: urinary incontinence, delirium and polypharmacy in elderly patients. CMAJ. 1997;157(8):1071-1077.

57. Talasz H, Lechleitner M. Polypharmacy and incontinence. Z Gerontol Geriatr. 2012;45(6):464-467.

58. Urinary Incontinence Guideline Panel. Urinary Incontinence in Adults: Clinical Practice Guideline. Rockville, MD: Agency for Health Care Policy and Research, Public Health Service; 1992.

59. Jones SA, Bhandari S. The prevalence of potentially inappropriate medication prescribing in elderly patients with chronic kidney disease. Postgrad Med J. 2013;89(1051):247-250.

60. Blix HS, Viktil KK, Moger TA, Reikvam A. Use of renal risk drugs in hospitalized patients with impaired renal function - an underestimated problem? Nephrol Dial Transplant. 2006;21(11):3164-3171.

61. Zahorec R. Ratio of neutrophil to lymphocyte counts - rapid and simple parameter of systemic inflammation and stress in critically ill. Bratisl Lek Listy. 2001;102(1):5-14. English, Slovak.

62. Ateş F, Yaraş S, Sarıtaş B, Altıntaş E, Sezgin O, Örekici G. Does neutrophil to lymphocyte ratio in peripheral blood predict endoscopic erosive esophagitis? Endoscopy. 2011;19(3):88-90.

63. Kaya MG. Inflammation and coronary artery disease: as a new biomarker neutrophil/lymphocyte ratio. Turk Kardiyol Dern Ars. 2013; 41(3):191-192. English.

64. Bhat T, Teli S, Rijal J, et al. Neutrophil to lymphocyte ratio and cardiovascular diseases: a review. Expert Rev Cardiovasc Ther. 2013;11(1): 55-59.

65. Grubb BP. Postural tachycardia syndrome. Circulation. 2008;117(21): 2814-2817.

66. Alwan A. Global Status Report on Noncommunicable Diseases. Geneva: World Health Organization; 2010
Clinical Interventions in Aging

\section{Publish your work in this journal}

Clinical Interventions in Aging is an international, peer-reviewed journal focusing on evidence-based reports on the value or lack thereof of treatments intended to prevent or delay the onset of maladaptive correlates of aging in human beings. This journal is indexed on PubMed Central, MedLine,

\section{Dovepress}

CAS, Scopus and the Elsevier Bibliographic databases. The manuscript management system is completely online and includes a very quick and fair peer-review system, which is all easy to use. Visit http://www.dovepress. com/testimonials.php to read real quotes from published authors. 